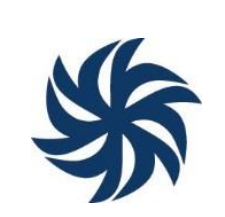

\title{
NEOINSTITUCIONALISMO, COMPORTAMENTO PARLAMENTAR E INTERPRETAÇÃO CONSTITUCIONAL
}

\author{
NEOINSTITUTIONALISM, PARLIAMENTARY BEHAVIOR AND \\ CONSTITUTIONAL INTERPRETATION
}

\section{NEOINSTITUCIONALISMO, COMPORTAMIENTO PARLAMENTARIO E INTERPRETACIÓN CONSTITUCIONAL}

\author{
Livia dos Santos Sena ${ }^{1}$
}

\begin{abstract}
Resumo: O comportamento parlamentar é tema pouco explorado pelos juristas no Brasil. Comumente referido como objeto da Ciência Política, a teoria constitucional brasileira pouco se preocupou em analisar sua relação com a interpretação constitucional realizada no dia-a-dia da política ordinária. A partir de uma leitura interdisciplinar, com base no método exploratório, o estudo pretende expor o paradigma teórico do neoinstitucionalismo da escolha racional, que figura como aspecto central da teoria do comportamento parlamentar, valendo-se da sua contribuição para avaliar o impacto das instituições na interpretação constitucional legislativa. Conclui, ao final, que faltam estudos jurídicos que considerem as implicações institucionais na interpretação da Constituição.
\end{abstract}

Palavra-chave: Neoinstitucionalismo; Teorias de Organização Legislativa; Comportamento Parlamentar; Interpretação Constitucional Legislativa.

\begin{abstract}
Parliamentary behavior is a subject that is under explored by jurists in Brazil. Commonly referred to as the object of political science, Brazilian constitutional theory was little concerned with analyzing its relationship with the constitutional interpretation performed on the daily basis of ordinary politics. Based on an interdisciplinary reading, using the exploratory method, the study intends to expose the theoretical paradigm of neoinstitutionalism of rational choice, which appears as a central aspect of the theory of parliamentary behavior, using its contribution to evaluate the impact of institutions on legislative constitutional interpretation. It concludes, in the end, that legal studies are lacking to consider institutional implications in the interpretation of the Constitution.
\end{abstract}

Keywords: Neoinstitutionalism; Theories of Legislative Organization; Parliamentary Behavior; Legislative Constitutional Interpretation.

\footnotetext{
${ }^{1}$ Procuradora da Universidade do Estado do Rio de Janeiro. Graduada em Direito na Universidade Federal do Rio de Janeiro. Mestranda em Direito Público na Universidade do Estado do Rio de Janeiro. E-mail: livia.s.sena@gmail.com
} 
Resumen: El comportamiento parlamentario es un tema poco explorado por los juristas en Brasil. Comúnmente conocida como el objeto de la ciencia política, la teoría constitucional brasileña estaba poco preocupada por analizar su relación con la interpretación constitucional realizada diariamente en la política ordinaria. Basado en una lectura interdisciplinaria, usando el método exploratorio, el estudio pretende exponer el paradigma teórico del neoinstitucionalismo de la elección racional, que aparece como un aspecto central de la teoría del comportamiento parlamentario, utilizando su contribución para la evaluación del impacto de las instituciones en la interpretación constitucional legislativa. Concluye, al final, que faltan estudios jurídicos que consideran las implicaciones institucionales en la interpretación de la Constitución.

Palabras clave: Neoinstitucionalismo; Teorías de la Organización Legislativa; Comportamiento Parlamentario; Interpretación Constitucional Legislativa.

\section{Introdução}

Neoinstitucionalismo é um rótulo que comporta versões bastante diversificadas. O movimento, que trouxe uma ressignificação do papel das instituições na vida política e social, se espalhou por diversos ramos das ciências humanas ${ }^{2}$. Em comum, as variadas correntes de pensamento que se autointitulam neoinstitucionalistas apresentam como traço de identidade a preocupação institucional com o comportamento humano, que ao mesmo tempo influencia e é influenciado pelo arranjo institucional vigente (TOSTA, 2019, p. 63).

Na Ciência Política, há três variantes claramente identificáveis entre os teóricos: o neoinstitucionalismo histórico, o neoinstitucionalismo sociológico e o neoinstitucionalismo da escolha racional. Longe de configurar uma teoria unificada, os vários "neoinstitucionalismos" evoluíram de forma independente - o que se verifica pela ausência de referência cruzada entre os autores - e atribuíram ao objeto central de análise - as instituições - definições imprecisas, o que torna falha qualquer tentativa de teorizá-las em conjunto (HALL; TAYLOR, 2003, p. 193194).

Não obstante, embora sigam linhas interpretativas bastante divergentes entre si, há dois pontos de contato entre as três versões que permitem sua categorização sob mesmo rótulo: surgem como uma reação ao behaviorismo e buscam desvendar a influência das instituições nos resultados políticos e sociais (SANTOS, 2006, p. 40). São essas características centrais que inserem o estudo do neoinstitucionalismo na base de qualquer análise sobre o comportamento parlamentar dos agentes políticos.

$\mathrm{Na}$ teoria jurídica, essa "virada institucional" é mais recente, tendo como marco teórico o artigo Interpretation and Institutions, de Cass Sunstein e Adrian Vermeule, escrito em 2002 (SUNSTEIN; VERMEULE, 2002). ${ }^{3} \mathrm{O}$ argumento das capacidades institucionais formulado pelos autores inspirou um giro pragmático na teoria da interpretação, que absorveu a

\footnotetext{
2 "Há pelo menos três áreas das ciências humanas nas quais, nos últimos quarenta anos, ocorreu a retomada do viés institucional como premissa analítica - a Economia, a Sociologia e a Ciência Política” (PERES, 2008, p. 54).

${ }^{3}$ Embora não tenha sido o primeiro artigo a tratar sobre o tema no Direito, certamente foi o mais influente. (TOSTA, 2019, p. 67).
} 
preocupação em considerar as instituições reais, não idealizadas, deslocando a discussão sobre "como" interpretar para "quem" deve interpretar (TOSTA, 2019, p. 68).

Partindo destas premissas, o objetivo do presente artigo é abordar a influência das instituições no comportamento parlamentar e como isso afeta a interpretação constitucional realizada pelo legislador. No debate estadunidense, a avaliação da responsabilidade constitucional do Congresso é permeada por argumentos institucionais que revelam os vícios e virtudes de uma interpretação constitucional fora das Cortes. A ideia, portanto, é trazer uma abordagem interdisciplinar que confira maior densidade ao estudo do papel do Poder Legislativo na persecução de fins constitucionais.

Este trabalho tem um viés eminentemente descritivo-exploratório. A primeira parte será dedicada a uma revisão sobre os diferentes tipos de neoinstitucionalismo e como a teoria foi desenvolvida pelos cientistas políticos estadunidenses. A segunda parte fará um breve retrospecto sobre as teorias de organização legislativa, que disputam entre si a melhor justificativa para a estabilidade do sistema político. A terceira parte, por fim, buscará contribuir para o desenvolvimento de uma teoria de interpretação constitucional legislativa à luz da Ciência Política, levando em consideração o impacto de elementos institucionais.

\section{Neoinstitucionalismo na Ciência Política}

Há certo senso comum na literatura política estadunidense de que os congressistas priorizam sempre a reeleição (LIMONGI, 1994, p. 4). Deve-se a David Mayhew (MAYHEW, 2004) o conceito de conexão eleitoral, segundo o qual os parlamentares agem movidos pelo desejo de permanecer no poder, preferindo políticas que beneficiem diretamente seus eleitores, aumentando assim as chances de reeleição. Essa é a premissa básica de toda a discussão que se seguirá, já que é praticamente unânime dentre os cientistas políticos que a reeleição é a prioridade número um de qualquer político.

Nesse contexto, desenvolveu-se no início da década de 1960 entre os cientistas políticos a tese de que as leis seriam simplesmente decisões coletivas tomadas a partir do somatório de preferências individuais manifestadas a partir da possibilidade de maximização das chances de reeleição. Esse era o paradigma do comportamentalismo ${ }^{4}$, dominante antes do advento do neoinstitucionalismo, que teve sua origem nos estudos formulados por teóricos de escolha racional que começaram a questionar essa premissa.

\footnotetext{
${ }^{4} \mathrm{O}$ comportamentalismo, por sua vez, surgiu em reação ao antigo institucionalismo. A propósito, esta a razão do termo "neoinstitucionalismo", que surgiu como uma terceira via que mescla elementos do comportamentalismo e elementos do antigo institucionalismo (PERES, 2008, p. 54).
} 
Assim, o neoinstitucionalismo surgiu como uma reação à "insuficiência de uma explicação voltada exclusivamente à ação dos indivíduos, em que se faz tábula rasa do contexto institucional da esfera estritamente política." (PERES, 2008, p. 54). Os agentes políticos agem dentro de uma estrutura institucional que delimita suas possibilidades de atuação. Afinal, testada a hipótese empiricamente, qual seria o resultado de uma política escolhida pura e simplesmente a partir do somatório das preferências individuais de cada membro do Congresso?

Uma das respostas a essa pergunta que acabou alavancando o movimento neoinstitucionalista foi elaborada por Kenneth Arrow, e ficou conhecida como Teorema da Impossibilidade (ARROW, 1970). Segundo o autor, seria impossível antecipar o resultado do processo decisório coletivo exclusivamente por meio do conhecimento prévio das preferências individuais. Havendo pelo menos três indivíduos votantes e três opções de voto, toda decisão social fundada na regra da maioria seria intrinsecamente instável e indeterminável a priori. A teoria retrata, em verdade, uma versão mais sofisticada do paradoxo de Condorcet (ARROW, 1970, p. 93).

No século XVIII, o matemático francês Marquês de Condorcet identificou o seguinte paradoxo na regra da maioria: se há ao menos três agentes votantes (A, B e C), três opções de voto $(\mathrm{X}, \mathrm{Y}$ e $\mathrm{Z})$ e as preferências individuais dos agentes não coincidem, significa que, nas votações por pares, $\mathrm{X}$ pode ganhar de $\mathrm{Y}$, Y pode ganhar de $\mathrm{Z}$ e $\mathrm{Z}$ pode ganhar de $\mathrm{X}$. Assim, a escolha de uma política por meio da aplicação da regra da maioria poderia levar a resultados circulares e votações intermináveis, o que abriria espaço para decisões arbitrárias (ARROW, 1970, p. 94).

Esse cenário de indeterminação aplicado ao processo político revela que, mesmo que as preferências individuais de cada votante sejam bem delineadas, o resultado da decisão coletiva variará a depender da ordem de votação, não sendo possível estabelecer uma única decisão coletiva pela agregação das preferências individuais. Em síntese, os ciclos de votação vão definir o resultado, abrindo espaço para manipulação da decisão por quem detém o poder de agenda (LIMONGI, 1994, p. 5-6). Logo, o sistema majoritário não conduziria ao equilíbrio, não havendo uma preferência coletiva claramente identificável.

Observa-se, portanto, que o processo de retomada do viés institucional na análise política sofreu forte influência do comportamentalismo estudado pela economia, "assentado em premissas básicas acerca das motivações e das preferências dos indivíduos e de seu mecanismo racional - calculista e egoísta - de tomada de decisão diante de alternativas excludentes" (PERES, 2008, p. 62). ${ }^{5}$ A análise econômica do comportamento humano acabou sendo

\footnotetext{
5 "Em relação a isso, é importante destacar que alguns economistas - tais como Schumpeter (1942), Arrow (1951), Downs (1957) e Buchanan e Tullock (1962) - contribuíram enormemente para tal atração, na medida em que, desde os anos de 1940, já vinham utilizando modelos econômicos de pensamento na análise do comportamento político, e, desse modo, acabaram sendo o ponto de partida para a "revolução" neo-institucional na política." (PERES, 2008, p. $62)$.
} 
absorvida em parte pelos críticos do behaviorismo, que começaram a refutar a perspectiva individualista da teoria.

Com o resgate do paradoxo de Condorcet por Arrow, a Ciência Política começou a voltar os olhos para a tomada de decisões coletivas fundadas na agregação de preferências pessoais, evidenciando as falhas de uma análise puramente egoística da atuação dos parlamentares. Afinal, o Teorema da Impossibilidade aponta para a inexistência de um arranjo institucional fundado no princípio majoritário capaz de fornecer uma única solução e de promover estabilidade (SANTOS, 2006, p. 32).

A segunda tese que marcou a origem da teoria neoinstitucionalista foi o Teorema do Caos de Richard McKelvey (MCKELVEY, 1976). De acordo com o autor, se o somatório das preferências individuais puder gerar resultados potencialmente cíclicos quando confrontados em votação por maioria, o agente que tem o poder de agenda poderá conduzir o processo de escolha a qualquer resultado, bastando ordenar as alternativas de forma inteligente. ${ }^{6}$ Partindo-se desta premissa, o arranjo dos ciclos de votação influencia de forma decisiva o resultado do processo decisório coletivo.

Assim, a depender da ordem de votação, qualquer resultado é possível, até mesmo a opção que ocupa o último lugar nas preferências de todos pode se sagrar vencedora, pois havendo um agente que exerce controle total sobre a agenda, em tese este indivíduo pode manipulá-la de modo a construir o cenário que lhe trouxer as maiores vantagens (MCKELVEY, 1976, p. 480). McKelvey colocou em evidência o problema da intransitividade das decisões sociais, onde quem controla a agenda pode assegurar qualquer resultado dentro das alternativas que ele mesmo estabelecer, independentemente das preferências individuais iniciais dos votantes. $^{7}$

Essas duas formulações teóricas exerceram influência significativa no estudo do processo decisório no interior do Congresso estadunidense. A conclusão que se extrai dos teoremas é que as decisões tomadas por maioria são intrinsecamente instáveis. Portanto, esses autores colocam em xeque a perspectiva comportamentalista da Ciência Política que, até então, focava nas preferências individuais de cada agente político. Se tomada a ferro e fogo, a ótica behaviorista levaria a uma instabilidade nociva às instituições democráticas.

\footnotetext{
6 "It follows from the above consideration that if any one voter, say the 'Chairman', has complete control over the agenda (in the sense that he can choose, at each stage of the voting, any proposal to be considered next) that he can construct an agenda which will arive at any point in space, in particular at his ideal point." (MCKELVEY, 1976, p. 481).

7 “A conclusão a que chega McKelvey é de que pode não haver qualquer relação entre as preferências individuais e o resultado final. Um definidor de agenda astuto será capaz de obter qualquer resultado, independente da configuração inicial das preferências" (LIMONGI, 1994, p. 8).
} 
Todavia, apesar do cenário desalentador descrito por Arrow e McKelvey, na prática as democracias contemporâneas são regidas pela regra da maioria e, ainda assim, apresentam elevado grau de estabilidade. Os famosos Teoremas da Impossibilidade e do Caos não se comprovam empiricamente. Consolida-se, então, o ambiente perfeito para a ascensão do neoinstitucionalismo, que aposta nas instituições como resposta para a estabilidade. As instituições não apenas induzem o equilíbrio, mas também exercem papel fundamental no resultado político substantivo (LIMONGI, 1994, p. 9).

Neste ponto, um breve aparte se faz necessário. Sem embargo da centralidade das instituições para a teoria neoinstitucionalista, não há uma definição unívoca do que se entende por instituição. Cada vertente a define a seu próprio modo, mas de forma genérica é possível considerar como tais procedimentos, leis, normas e estruturas organizacionais que condicionam o comportamento, conferindo uma explicação racional para os resultados tomados de maneira coletiva (LIMONGI, 1994, p. 9).

As três escolas da teoria neoinstitucionalista constituem, na verdade, três métodos de análise com enfoques diferentes sobre o impacto das instituições no comportamento político, que variam desde sua origem histórica até o conceito de instituição e o peso atribuído às preferências pessoais e à racionalidade individual. $\mathrm{O}$ objetivo, todavia, é comum a todas elas: buscar desvendar a real extensão da influência das instituições na tomada de decisões coletivas pelos parlamentares.

Começando pelo neoinstitucionalismo histórico, seus autores consideram que a estrutura organizacional das instituições sociais ou econômicas era a principal determinante do comportamento dos atores políticos e dos resultados dele advindos, dando especial destaque às assimetrias de poder relacionadas ao desenvolvimento das instituições. Os teóricos da vertente histórica situam as instituições "numa cadeia causal que deixe espaço para outros fatores, em particular os desenvolvimentos socioeconômicos e a difusão das ideias" (HALL; TAYLOR, 2003, p. 201), e definem o termo instituição como normas e convenções relativas à organização da comunidade ou da economia.

Por sua vez, o neoinstitucionalismo sociológico tem como categorias centrais os valores e hábitos, sendo o desempenho do indivíduo condicionado pelo entorno cultural e social e pelas próprias instituições, concebidas estas como marcos de referência cultural. ${ }^{8}$ Segundo Hall e Taylor, as formas e procedimentos institucionais das organizações modernas deveriam ser consideradas como práticas culturais, que "seriam incorporadas às organizações, não necessariamente porque aumentassem sua eficácia abstrata (em termos de fins e meios), mas em consequência do mesmo tipo de processo de transmissão que dá origem às práticas culturais em geral" (HALL; TAYLOR, 2003, p. 208).

\footnotetext{
${ }^{8} \mathrm{O}$ problema do neoinstitucionalismo sociológico é a dificuldade de se distinguir instituição e cultura ao considerar que instituições são construções sociais que regulam as interações dos indivíduos. (LEONE, 2015, p. 94).
} 
Por fim, o neoinsitucionalismo da escolha racional merece análise mais detida. As duas vertentes anteriores, de caráter marcadamente determinista, não angariaram muitos adeptos, embora tenham contribuído para o desenvolvimento de uma abordagem mais realista e contextual. Hoje, a teoria neoinstitucionalista consolidou sua hegemonia na Ciência Política (PERES, 2008, p. 53), havendo relativo consenso em relação à adoção do paradigma da escolha racional (SANTOS, 2006, p. 25). A teoria da escolha racional surge no segundo pós-guerra para dar conta da complexidade dos fenômenos sociais, transpondo o raciocínio da abordagem econômica para a Ciência Política.

Assim, a escolha racional se caracteriza pela importação da "nova economia da organização" para a Ciência Política, que tem como eixo principal a análise dos custos de transação para o funcionamento das instituições (HALL; TAYLOR, 2003, p. 203). Parte, portanto, da concepção de homo economicus para tentar oferecer uma resposta aos fundamentos das ações humanas diante de complexas relações sociais (SANTOS, 2006, p. 24). Não por acaso, a teoria apresenta como principais derivações a public choice e a social choice (SANTOS, 2006, p. 26).

De modo geral, os teóricos do neoinstitucionalismo da escolha racional enfatizam o sistema de comissões e as lideranças políticas dotadas de autoridade dentro do Congresso, buscando enfrentar o modo como as normas internas do Poder Legislativo estadunidense conformam o comportamento dos seus agentes. Partem do pressuposto de que os parlamentares compartilham algumas preferências e são guiados por um raciocínio utilitário para a maximização de seus próprios interesses, atuando quase sempre de forma estratégica e calculada (SANTOS, 2006, p. 204-205).

Nesse contexto, interessante a precisa análise de Peres (2008):

$\mathrm{Na}$ vertente da Ciência Política - em sua quase totalidade adepta ao "institucionalismo da escolha racional" -, o que prevalece é concepção de que as instituições interagem com as preferências já dadas, provocando um processo de "transição" destas em relação aos objetos, de acordo com uma "escala de utilidades". Ou seja, as instituições, como formas de restrição das decisões em favor daquilo que ocuparia o primeiro lugar numa dada escala de preferências, provocaria o deslocamento dessa escolha para objetos outros que ocupariam ou o segundo, ou o terceiro, ou o quarto lugar de suas preferências, e assim por diante. Nesse caso, então, não se mostram relevantes nem o processo de socialização, nem a formação das preferências, uma vez que o problema é exclusivamente circunscrito ao processo da tomada de decisão num contexto em que as preferências já estão estruturadas e que são restringidas por certo tipo de arranjo institucional (PERES, 2008, p. 64). 
O aprofundamento dos estudos dentro da teoria da escolha racional levou ao surgimento de três versões para a explicação da estabilidade no interior do Parlamento, que são as chamadas teorias de organização legislativa: distributivista, informacional e partidária (SANTOS, 2006, p. 48). As teorias sustentam que o funcionamento do Congresso estadunidense é mais bem compreendido à luz da ideia de custos de transação. Analisam, cada uma a seu modo, como as instituições induzem equilíbrio. ${ }^{9}$ A elas será dedicada a próxima seção.

\section{Teorias de organização legislativa}

As teorias de organização legislativa partem do pressuposto de que a política no interior do Congresso reflete os ganhos advindos da cooperação entre os parlamentares, orquestrada com o intuito de amplificação de suas preferências individuais. Cada uma das teorias analisa sob uma perspectiva diferente como as instituições promovem a estabilidade do sistema político em um ambiente de interesses conflitantes, compartilhando da mesma premissa de que a prioridade de todos os agentes políticos é a reeleição.

Majoritariamente, os neoinstitucionalistas se dividem entre a teoria distributivista e a teoria partidária, com certa predominância da primeira. Em verdade, a versão distributivista era hegemônica até começar a ser questionada por autores que duvidaram da pertinência de uma teoria de caráter clientelista que enfatiza o papel das comissões. Do embate surgiram as correntes informacional e partidária, que deslocam o foco para o papel das informações e dos partidos políticos na definição da ação coletiva (LIMONGI, 1994, p. 3).

Resistente a críticas, a teoria distributivista ainda conserva sua prevalência dentre os teóricos da escolha racional. Nesse modelo, o Congresso é visto como um mercado de trocas onde preferências produzem equilíbrio (SANTOS, 2006, p. 50). A teoria enxerga as comissões parlamentares como ambientes favoráveis a ganhos de troca, onde as decisões políticas são tomadas em um contexto plural, formado por preferências heterogêneas, o que viabiliza a barganha (SHEPSLE; WEINGAST, 1994, p. 152). As comissões aproximam os parlamentares e evidenciam os conflitos de interesses, que demandam concessões recíprocas para que sejam satisfeitos na maior escala possível.

Nesse cenário, a troca surge como uma decorrência necessária da heterogeneidade de preferências. Dada a regra da maioria, se todos os agentes políticos forem intransigentes em relação às suas preferências, nenhum deles atingirá o resultado pretendido, posto que incompatíveis entre si. Porém se, ao contrário, os agentes políticos seguirem uma lógica

\footnotetext{
9 "No geral, as teorias positivas da organização legislativa primam por tentar explicar como indivíduos presumivelmente individualistas e clientelistas podem estabelecer contratos (logrolls) suficientemente estáveis e capazes de superar a heterogeneidade de suas preferências em direção à consecução de um bem comum ou da ação coletiva" (NASCIMENTO, 2010, p. 366).
} 
cooperativa, realizando trocas, todos podem ganhar em alguma medida (NASCIMENTO, 2010, p. 370). O ambiente, portanto, induz cooperação. Nas palavras de Limongi (1994),

\begin{abstract}
Embora imersos em uma situação conflituosa, lutando por se apropriar de recursos escassos, os congressistas podem sair ganhando se cooperarem, posto que as políticas que interessam o representante do distrito A só serão aprovadas se contarem com o apoio do representante do distrito B. De fato, pode-se dizer que existe um mercado de votos no interior do Congresso. Políticas são aprovadas mediante a troca de votos: eu voto pela política que lhe interessa desde que você vote pela política que me interessa. Esta troca de votos é conhecida na literatura por logroll (LIMONGI, 1994, p. 12).
\end{abstract}

Assim, parte-se do pressuposto de que são as vantagens eleitorais que ditam o comportamento dos parlamentares, que agem guiados pelo objetivo de atender às demandas do seu eleitorado, com os olhos nas eleições vindouras. Nesse sistema, as comissões exercem papel fundamental ao permitirem ganhos de troca, já que gozam de poderes significativos na definição dos resultados políticos. As comissões são, portanto, o alicerce da organização legislativa no Congresso (SANTOS, 2006, p. 54).

Nessa conjuntura, o modelo distributivo enfatiza o modo de distribuição de recursos diante da infinidade de preferências individuais e encontra no sistema de comissões a chave para compreender essa dinâmica, pois elas tornam a barganha conveniente e garantem a observância dos acordos (NASCIMENTO, 2009, p. 375). Em suma, a teoria encontra as explicações sobre o funcionamento do Congresso Nacional no caráter centralizador das comissões, reconhecendo que a concentração de poderes que representa é determinante na tomada de decisão.

Em comum com a teoria distributivista, a teoria informacional tem o reconhecimento das comissões como o epicentro da organização legislativa no Congresso. Entretanto, a vertente informacional sustenta que o Congresso promove esforços para garantir que as decisões sejam tomadas após angariar o maior volume de informação possível, onde não são as preferências e sim as estruturas que induzem equilíbrio (SANTOS, 2006, p. 50). A ideia é que os parlamentares se organizam para diminuir a incerteza que se coloca diante de informações imperfeitas, e não para obter ganhos de troca.

Segundo a teoria, o papel das comissões é produzir e disseminar informação, com o objetivo de reduzir as assimetrias informacionais e, consequentemente, as incertezas acerca dos possíveis resultados de determinada política (SANTOS, 2006, p. 58). O cerne da teoria é que os agentes políticos agem com o fim de reduzir o déficit informacional para trazer maior previsibilidade quanto ao resultado. As instituições são vistas como instrumentos para promover a informação. Quanto mais bem informado o agente político, menores são os riscos decorrentes da incerteza. 
Portanto, o arranjo institucional pode oferecer incentivos para que as comissões se especializem e adquiram mais poderes por meio da concentração de informação (NASCIMENTO, 2010, p. 380). Nesta teoria, o debate tem um valor instrumental de disseminar conhecimento. Conforme aduz Limongi, "congressistas têm incertezas e alteram suas crenças a partir da troca de informações. Quanto maior a quantidade de informação tornada pública, via debate e deliberação, tanto melhor a qualidade da decisão" (LIMONGI, 1994, p. 37).

Por sua vez, a teoria partidária promove uma mudança radical de perspectiva. Nesse modelo, os partidos políticos são o personagem principal da organização congressual, pois são eles que resolvem os problemas de ação transindividual. Em outras palavras, a versão partidária foca no papel dos partidos para a solução de dilemas coletivos, que são situações em que "o comportamento racional de uma parte dos indivíduos pode levar a resultados unanimemente não-preferidos" (SANTOS, 2006, p. 63) por meio da concentração de poderes em uma autoridade específica. No âmbito dos partidos, essas autoridades são os líderes partidários.

De acordo com esta vertente, os atores políticos mais influentes são os representantes do partido majoritário, que controlam o processo legislativo e as comissões. Assim, a influência das comissões só se verifica quando elas corporificam os interesses partidários. Nesse sistema, o segredo para a compreensão do comportamento parlamentar está nos partidos, que formam uma espécie de "cartel legislativo" (NASCIMENTO, 2010, p. 385), valendo-se de ferramentas institucionais para unir os parlamentares em torno de preferências comuns.

Nota-se, portanto, que as teorias positivas de organização legislativa tentam identificar a origem da estabilidade do sistema político no Congresso estadunidense. Independentemente da vertente que se adote, o objetivo é comum a todas elas: elucidar a questão de como indivíduos com motivações egoísticas e pretensões conflitantes alcançam o consenso e impedem a transitoriedade das decisões coletivas, gerando equilíbrio. Ora focando nas comissões, ora nas informações, ora nos partidos, cada teoria busca encontrar uma explicação institucional para o comportamento parlamentar.

A versão distributivista, majoritária no contexto estadunidense e importada por grande parte dos cientistas políticos brasileiros, encontra nas políticas clientelistas a estratégia eleitoral perfeita para garantir a reeleição. Em busca de benefícios particularizados, direcionados aos seus eleitores, e custos difusos, os legisladores encontram-se em uma situação de conflito constante, o que só pode ser resolvido por meio de um acordo que gere a troca de votos (LIMONGI, p. 1994, p. 12). A estabilidade, portanto, provém da ajuda mútua, que é proporcionada pela estruturação em comissões.

Esta construção teórica está na base dos estudos de muitos pesquisadores do Congresso estadunidense. É importante ter esta informação em mente quando o propósito é analisar o desempenho constitucional do legislador. Especialmente em razão do destaque que o modelo distributivo confere às comissões e ao arranjo institucional do Congresso, a academia 
estadunidense oferece contribuições valiosas para a análise dos aspectos institucionais capazes de afetar o endereçamento de questões constitucionais pelo legislador. É do que se passará a tratar.

\section{Comportamento parlamentar e interpretação constitucional}

A teoria neoinstitucionalista e o paradigma da escolha racional estão por trás das mais relevantes produções acadêmicas sobre o Poder Legislativo nos Estados Unidos. Ainda quando não reconhecido expressamente, o neoinstitucionalismo da escolha racional remanesce como pano de fundo das análises políticas do Congresso estadounidense. Não por acaso, os estudos sobre a relação entre o Congresso e a Constituição naquele país muitas das vezes partem de uma ótica institucional, buscando lançar luzes sobre a dimensão institucional da interpretação da Constituição pelo legislador.

Como não poderia ser diferente, a premissa da busca pela reeleição que está subjacente a todas as teorias positivas de organização legislativa contribui de forma significativa para a interpretação constitucional. Nos anos 2000, pesquisas indicaram que os legisladores tendem a enfrentar discussões constitucionais nas áreas políticas mais próximas das preocupações de seus eleitores (PEABODY, 2005, p. 59). Desse modo, a accountability eleitoral exerce papel determinante na interpretação constitucional, tendo em vista que os eleitores podem preferir um representante que leve a sério considerações de ordem constitucional na votação de projetos (GARRET e VERMEULE, 2005, p. 246).

Atualmente, não há dúvidas de que a capacidade do legislador de atuar como intérprete constitucional é moldada pela opinião de seus eleitores, o que impacta diretamente na posição constitucional que será defendida no Congresso. Por exemplo, a base eleitoral de um agente político que foi eleito por levantar uma bandeira em favor de grupos LGBTQI+ espera que ele adote posições firmes em relação à liberdade sexual e de gênero. Dificilmente esse parlamentar será reeleito se desconsiderar tais aspectos nas deliberações de que vier a participar.

Ainda na década de 1980, Abner Mikva e Louis Fisher travaram intenso debate sobre a capacidade institucional de o Poder Legislativo realizar interpretação constitucional de forma responsável e efetiva. Tendo profissionalmente transitado entre o Congresso e o Poder Judiciário, Mikva era totalmente cético quanto a esta possibilidade e um dos argumentos era que, na maior parte dos casos, os votos são determinados pelos líderes partidários ou compromissos políticos fruto de barganha (MIKVA, 1983, p. 609). Essa visão, em particular, encontra amparo nas teorias distributivista e partidária, que inserem a negociação e a posição do partido no centro da tomada de decisão coletiva. 
Em resposta, Fisher argumentou que o desenho constitucional jamais permitiu que o Congresso se esquivasse do dever de interpretar a Constituição, destacando o papel das comissões parlamentares justamente no sentido oposto. De acordo com o autor, nos Estados Unidos o Joint Comittee foi criado com competência para tratar especificamente de assuntos de interesse vital para o Congresso e dos efeitos das decisões judiciais nas suas prerrogativas institucionais, revelando a importância das comissões na avaliação da constitucionalidade das medidas propostas (FISHER, 1985, p. 728).

O embate entre os autores evidencia a posição central que a perspectiva distributivista ocupa na discussão acerca da capacidade de interpretação constitucional do legislador. De fato, as comissões desempenham papel fundamental na deliberação sobre questões constitucionais. No Brasil, as Comissões de Constituição e Justiça são um exemplo da relevância da concentração e especialização de funções no interior do Parlamento. Não seria exagero afirmar que as comissões são a instituição de maior destaque na interpretação constitucional realizada pelo Congresso Nacional.

Ao menos é o que sugere a leitura dos relatórios das Comissões de Constituição e Justiça da Câmara dos Deputados e do Senado Federal. Veja-se, por exemplo, os pareceres apresentados durante a tramitação da proposta de emenda à Constituição para a Reforma da Previdência. Concorde-se ou não com o juízo de constitucionalidade das comissões, os relatórios enfrentaram adequadamente diversos pontos sensíveis em mais de 50 páginas de fundamentação cada um. É de se reconhecer que o Congresso Nacional vem levando a interpretação constitucional a sério.

Poder-se-ia argumentar que uma análise distributivista das comissões incumbidas do controle da constitucionalidade de atos normativos inseriria a Constituição no conjunto das moedas de troca existentes entre os legisladores. Se A pretende aprovar a lei X em benefício de seus eleitores e B pretende aprovar a lei Y em benefício dos seus, bastaria que negociassem os votos pela constitucionalidade das leis. Todavia, há dois outros aspectos institucionais a se considerar nessa equação - a possibilidade de controle de constitucionalidade judicial e a necessidade de fundamentação da decisão da própria comissão.

Começando pelo último, a fundamentação da decisão da comissão está relacionada à necessidade de deliberação parlamentar no âmbito das comissões. A própria deliberação, por si só, traz benefícios institucionais e processuais concretos no incremento da capacidade interpretativa do Congresso. ${ }^{10}$ No Brasil, as discussões da CCJ não se dão a portas fechadas. Pelo contrário, é elaborado um parecer pelo relator, que deverá ser votado pelos membros da

\footnotetext{
${ }^{10}$ Dentre os benefícios se destacam os incentivos à revelação de informações privadas, à exposição de visões extremas ao efeito moderador de diversos contra-argumentos, ao incremento da legitimidade das decisões tomadas por meio da apresentação de razões e à apresentação de justificativas públicas para as proposições (GARRET e VERMEULE, 2005, p. 248).
} 
comissão. Opinando pela inconstitucionalidade, o projeto é arquivado, cabendo recurso ao plenário. Opinando pela constitucionalidade, o projeto seguirá o trâmite regular.

Portanto, ainda que haja troca de votos pela constitucionalidade ou inconstitucionalidade de determinada proposição, as razões constitucionais devem ser exteriorizadas e serão submetidas a controle pelos demais membros da Casa. Mesmo que a motivação oculta do voto seja a barganha, deverão ser apresentados argumentos suficientes para sustentar a constitucionalidade ou inconstitucionalidade da medida. Desse modo, a necessidade de fundamentação constitucional do projeto constitui um limite importante para a negociação política.

Em segundo lugar, a mera possibilidade de controle judicial de constitucionalidade exige que a opção escolhida pelos congressistas possa ser reconduzida a fundamentos constitucionais. Em outras palavras, um projeto de lei claramente inconstitucional terá grandes chances de ser derrubado no Supremo. Se os legisladores dependem da efetividade daquela medida para sua reeleição, no mínimo se preocuparão em evitar editar uma lei inconstitucional. Não importa se o resultado é fruto de barganha, mas sim se é constitucionalmente adequado.

Esta circunstância ganha maior relevância ainda em um cenário de expansão da jurisdição constitucional, em que a Corte define grande parte da agenda política do país. Nesse contexto, é natural que os atores políticos levem em consideração precedentes da Suprema Corte ou tentem antecipar eventual posicionamento para evitar uma derrota no futuro - é a chamada "obediência antecipada" à jurisprudência da Corte Constitucional (TUSHNET, 2005, p. 271). Essa atuação estratégica é explicada em grande parte pela teoria da escolha racional, segundo a qual

\footnotetext{
É plausível que o comportamento de um ator é determinado não por forças históricas impessoais, mas por um cálculo estratégico, e, segundo, que esse cálculo é fortemente influenciado pelas expectativas do ator relativas ao comportamento provável dos outros atores. As instituições estruturam essa interação ao influenciarem a possibilidade e a sequência de alternativas na agenda, ou ao oferecerem informações ou mecanismos de adoção que reduzem a incerteza no tocante ao comportamento dos outros, ao mesmo tempo que propiciam aos atores "ganhos de troca", o que os incentivará a se dirigirem a certos cálculos ou ações precisas. Trata-se de um enfoque "calculador" clássico para explicar a influência das instituições sobre a ação individual (HALL; TAYLOR, 2003, p. 206).
}

Nesse sentido, é interessante a perspectiva estratégica empregada pela Teoria dos Jogos para explicar o comportamento político. Originalmente desenvolvida pelos economistas Oskar Morgenstern e John Von Neumann para a explicação do uso de estratégias racionais no estudo da matemática aplicada (NEUMANN; MORGENSTERN, 1972), a Teoria dos Jogos logo se 
disseminou pelos demais ramos da ciência. Centrada na análise do comportamento estratégico dos indivíduos em um cenário de custo-benefício incerto, fortemente dependente das escolhas de outros agentes, a formulação também deixou sua marca na Ciência Política.

Segundo a teoria, os agentes políticos, vistos como jogadores, buscam elaborar uma matriz de ganhos onde identificam as preferências de cada oponente e os ganhos delas decorrentes para ao final definir qual o resultado mais vantajoso. Desse modo, quando o número de rodadas é indefinido, os agentes costumam adotar posições cooperativas de modo a induzir a cooperação futura dos demais. São os típicos "jogos de compromisso", cujo raciocínio vale tanto para as negociações puramente políticas quanto para as interações entre o Congresso e a Suprema Corte na interpretação constitucional (DERBLI, 2015, p. 180-181).

Portanto, o instrumental teórico do neoinstitucionalismo da escolha racional mais contribui para a consideração de argumentos constitucionais que para sua negação. O jogo político não é incompatível com a seriedade de que a discussão sobre temas constitucionais deve se revestir. Ao contrário, o protagonismo da Suprema Corte é capaz de provocar o efeito inverso ao do judicial overhang ${ }^{11}$ temido por Tushnet e fazer com que os legisladores passem a atuar de forma mais séria e crítica a respeito da constitucionalidade das medidas, além de estimular a continuidade do debate interinstitucional, fomentando uma cultura de diálogo. ${ }^{12}$

Nesse cenário, vê-se que a interpretação constitucional realizada no interior do Congresso Nacional sofre forte impacto do arranjo institucional. Seja em relação a aspectos institucionais internos relativos ao próprio funcionamento do Poder Legislativo, seja em relação a aspectos institucionais externos relativos ao relacionamento entre os poderes, fato é que as instituições exercem papel fundamental na perfomance constitucional do legislador. Muitas das vezes, orientam a atuação política no sentido de levar a sério a constitucionalidade das propostas.

\footnotetext{
11 Entendido como o efeito de encorajar certa irresponsabilidade dos membros do Congresso na interpretação constitucional, já que sempre haverá alguém para supervisioná-lo. È descrita pelo autor na seguinte passagem: "Consider a situation in which members of Congress have a choice: They can enact a splashy statute that directly attacks a problem, albeit in a way that the courts will find unconstitutional, or they can enact a boring one, full of obscure details, that might be a bit less effective in achieving Congress's policy goals but that would be unquestionably constitutional. Presumably enacting a statute that advances policy goals is politically attractive, but sometimes enacting the splashy but unconstitutional statute may be even more politically attractive. Members then can take credit for trying to do something and blame the courts for their failure even though the other statute might have been both constitutional and nearly as effective in achieving Congress's policy goals" (TUSHNET, 2005, p. 271).

12 "Sob essa perspectiva, há espaço para que se analisem as interações entre os Poderes à luz da Teoria dos Jogos e, assim, identificar o equilíbrio de Nash ao longo das sucessivas rodadas: para o Poder Legislativo, estará, de forma geral, na edição de lei que, considerado o controle judicial de constitucionalidade, terá maiores possibilidades de ser preservada; simetricamente, para o Poder Judiciário, será verificada, em regra, na decisão judicial que, considerada a atividade legislativa voltada à superação dos precedentes judiciais (por exemplo, por intermédio de emenda constitucional), terá maiores possibilidades de se manter hígida." (DERBLI, 2015, p. 183).
} 
Assim, não é difícil perceber que a dinâmica do comportamento parlamentar tem muito a oferecer para a teoria constitucional, em especial para a interpretação legislativa. A bem da verdade, faltam estudos que considerem o desenho institucional do Congresso na análise do desempenho dos agentes políticos como intérpretes constitucionais. A ausência de trabalhos interdisciplinares gera um vácuo na teoria da interpretação constitucional que não caberia nos estreitos limites deste artigo. Espera-se apenas, ter sinalizado um horizonte a ser descortinado.

\section{Conclusão}

Desde o final do século XX, o neoinstitucionalismo da escolha racional tem sido o ponto referencial dos estudos legislativos nos EUA. Embora nosso Poder Legislativo tenha peculiaridades que tornam inviável uma importação integral da produção estadunidense, a investigação do comportamento parlamentar brasileiro tem muito a aprender com aquele que é considerado o maior Congresso do mundo. O avançado estágio da Ciência Política estadunidense contribui de forma significativa para o desenvolvimento de qualquer formulação teórica própria.

No Brasil, as abordagens trazidas pelas três versões do neoinstitucionalismo da escolha racional influenciaram em grande medida os estudos sobre o Congresso Nacional realizados a partir da Constituição de 1988 (PERES, 2008, p. 67). Por aqui, os cientistas políticos se dividem entre a teoria distributivista e a teoria partidária, que disputam qual a melhor resposta para estabilidade do nosso sistema político. Em verdade, os autores brasileiros trabalham com um certo hibridismo entre as duas formas, proveniente de uma adaptação às particularidades do nosso sistema político, o que torna tormentosa a tarefa de identificar qual versão prevalece (SANTOS, 2006, p. 96-99).

Entretanto, mais relevante que tentar encaixar os cientistas políticos brasileiros nas diferentes vertentes construídas pela doutrina estadunidense - após anos de estudos sobre um Congresso que conta com mais de dois séculos de história, diga-se de passagem -, é voltar os olhos para o impacto que a teoria neoinstitucionalista provocou nas pesquisas sobre o comportamento parlamentar no Brasil: deslocou o debate sobre sistema de governo e forma de governo para o debate sobre instituições conformadoras da atuação política coletiva.

Nesse contexto, o propósito de estudar a interpretação constitucional que é levada a efeito pelo legislador não prescinde de uma análise sobre os fatores que influenciam o comportamento parlamentar. Em busca desse arcabouço, mais político que jurídico, a pesquisa se deparou com uma vasta produção acadêmica no campo da Ciência Política que busca compreender o que está por trás do processo de elaboração das leis brasileiras. Não se pode deixar de notar como o Direito negligencia a Ciência Política no Brasil, como se dela pudesse se dissociar completamente. 
Talvez seja esse o legado mais importante dos estudos legislativos sobre o Congresso estadunidense: o caráter interdisciplinar. Naquele país, a fecunda produção acadêmica sobre a atuação do Poder Legislativo enquanto intérprete da Constituição está repleta de argumentos institucionais e políticos, revelando que a interpretação constitucional legislativa se situa no limiar entre Direito e Política. Não é improvável que no Brasil a evolução independente dos dois ramos seja a grande responsável pela ausência de trabalhos sobre a relação entre o Poder Legislativo brasileiro e a Constituição. É hora de rever esta relação.

Entre nós, o estudo do impacto das instituições no Direito Público é recente e caminha a passos lentos. O tema nunca havia despertado muita atenção até a disseminação da obra de Sunstein e Vermeule (SUNSTEIN; VERMEULE, 2002), que levantou a necessidade de se considerar o desenho institucional dos órgãos estatais responsáveis pela interpretação do Direito. A partir de então, começou-se a questionar as capacidades institucionais de intérpretes reais, inseridos em um complexo sistema de incentivos e limitações, onde as condições de atuação estão longe daquelas consideradas ideais.

Nessa ordem de ideias, transpor para a teoria jurídica o contexto institucional da atividade parlamentar implica esmiuçar a estrutura de incentivos inerente ao processo político decisório. Uma teoria que se preste a discorrer sobre as relações entre a Constituição e o legislador sem considerar o modo como o processo legislativo se desenvolve e quais os principais fatores que influenciam a tomada de decisão no Parlamento seria completamente descolada da realidade. Se o objetivo é enxergar a Constituição pelas lentes do legislador, não se pode fazer tábula rasa da esfera institucional.

Ao debruçar-se sobre a interpretação constitucional realizada no bojo do processo legislativo, o jurista encontrará um arsenal de instituições que condicionam a atuação dos agentes políticos e moldam sua relação com a Constituição. Portanto, integrar ao Direito a variada gama de pesquisa da Ciência Política soa como um caminho promissor para a compreensão da responsabilidade constitucional do legislador. Afinal, a chave para uma abordagem realista da interpretação da Constituição pelo Congresso Nacional está na raiz dos estudos legislativos: as instituições. 


\section{Referências}

ARROW, Kenneth J. Social Choice and Individual Values. Cowles Foundation for Research in Economics at Yale University. $2^{\text {nd }}$ ed. New Haven: Yale University,1970.

DERBLI, Felipe. Interações estratégicas entre os poderes no controle de constitucionalidade: aplicações da teoria dos jogos nos diálogos constitucionais. In: BRANDÃO, Rodrigo; BAPTISTA, Patrícia. (Org.). Direito público. Rio de Janeiro: Freitas Bastos, 2015. p. 177-204. v. 1.

FISHER, Louis. Constitutional Interpretation by Members of Congress. North Carolina Law Review, v. 63, p. 707-747, 1985.

GARRET, Elizabeth; VERMEULE, Adrian. Institutional Design of a Thayerian Congress. In: WhITTINGTON, Keith; DEVINS, Neal. (org.). Congress and the Constitution. London: Duke University Press, 2005. p. 241-265.

HALL, Peter A.; TAYLOR, Rosemary C. R. As três versões do neoinstitucionalismo. Lua Nova, n. 58, p. 193-223, 2003.

LEONE, José Antonio Rivas. Institucionalismo - neoinstitucionalismo y calidad de la democracia. Provincia, n. 33, p. 87-127, enero/junio 2015.

LIMONGI, Fernando. O novo institucionalismo e os estudos legislativos: a literatura norteamericana recente. Boletim Informativo Bibliográfico de Informação em Ciências Sociais, n. 37, p. 3-38, 1994.

MAYHEW, David R. Congress: The Electoral Connection. New Haven: Yale University Press, 2004.

MCKELVEY, Richard D. Intransitivities in Multidimensional Voting Models and Some Implications for Agenda Control. Journal of Economic Theory, v. 12, n. 3, p. 472-482, 1976.

MIKVA, Abner. How Well Does Congress Support and Defend the Constitution. North Carolina Law Review, v. 61, n. 4, p. 587-611, 1983.

NEUMANN, John Von; MORGENSTERN, Oskar. Theory of Games and Economic Behaviour. Princeton: Princeton University Press, 1972.

NASCIMENTO, Emerson Oliveira do. Os modelos da organização legislativa: distributivo, informacional e partidário. Revista Política Hoje, v. 366, n. 2, p. 365-397, 2010.

PEABODY, Bruce. G. Congressional Attitudes toward Constitutional Interpretation. In: WHITTINGTON, Keith; DEVINS, Neal. (org.) Congress and the Constitution. London: Duke University Press, 2005, p. 38-61.

PERES, Paulo Sérgio. Comportamento ou instituições?: a evolução histórica do neoinstitucionalismo da ciência política. Revista Brasileira de Ciências Sociais, v. 23, n. 68, p. 53-71, out. 2008.

SANTOS, Manoel Leonardo W. D. As teorias positivas sobre a organização do Legislativo e as explicações sobre o Congresso Nacional. 2006. 190 f. Dissertação (Mestrado em Ciência Política) - Departamento de Ciência Política, Universidade Federal de Pernambuco,2006.

SHEPSLE, Kenneth A.; WEINGAST, Barry R. Positive Theories of Congressional Institutions. Legislative Studies Quarterly, v.19, n. 2, p. 149-179, 1994. 
SUNSTEIN, Cass; VERMEUle, Adrian. Interpretation and Institutions. Public Law and Legal Theory Working Paper, n. 28, p.1-55, 2002.

TOSTA, André Ribeiro. Instituições e o direito público: empirismo, inovação e um roteiro de análise. Rio de Janeiro: Lumen Juris, 2019.

TUSHNET, Mark. Evaluating Congressional Constitutional Interpretation: some criteria and two informal case studies. In: WHITTINGTON, Keith; DEVINS, Neal. (org.). Congress and the Constitution. London: Duke University Press, 2005. p. 269-289.

Artigo submetido em: 2020-03-14

Reapresentado em: 2020-05-04

Aceito em: 2020-05-11 